\title{
Relationship Between Neutrophil-Lymphocyte Ratio and Microvascular Complications in Egyptian Patients with Type 2 Diabetes
}

\author{
Eman Youssef Moursy ${ }^{1}$, Magdy Helmy Megallaa ${ }^{1}$, Reham Fadl Mouftah ${ }^{2}$, Soha Magdy Ahmed ${ }^{3}$ \\ ${ }^{1}$ Unit of Diabetes \& Metabolism, Department of Internal Medicine, Faculty of Medicine, Alexandria University, Alexandria, Egypt \\ ${ }^{2}$ Department of Clinical Pathology, Faculty of Medicine, Alexandria University, Alexandria, Egypt \\ ${ }^{3}$ Alexandria Students Hospital, Ministry of Health, Alexandria, Egypt
}

Email address:

dr.emanyoussef@gmail.com (E. Y. Moursy),magdy_megallaa@yahoo.com (M. H. Megallaa),rfadl1@yahoo.com (R. F. Mouftah), soha-magdy@yahoo.com (S. M. Ahmed)

\section{To cite this article:}

Eman Youssef Moursy, Magdy Helmy Megallaa, Reham Fadl Mouftah, Soha Magdy Ahmed. Relationship Between Neutrophil-Lymphocyte Ratio and Microvascular Complications in Egyptian Patients with Type 2 Diabetes. American Journal of Internal Medicine.

Vol. 3, No. 6, 2015, pp. 250-255. doi: 10.11648/j.ajim.20150306.16

\begin{abstract}
Several epidemiological studies have shown that chronic inflammation plays a central role in the pathogenesis of diabetes and its various complications. Neutrophil-lymphocyte ratio (NLR) is a novel potential marker in determining inflammation. The aim of this study was to evaluate the relationship between diabetic microvascular complications, namely diabetic retinopathy, nephropathy, neuropathy, and neutrophil-lymphocyte ratio in type 2 diabetic patients. The study took place in the Unit of Diabetes \& Metabolism at the Faculty of Medicine, Alexandria University, Alexandria, Egypt, and included a total of 280 subjects, 200 male patients with type 2 diabetes, 108 of them having one or more microvascular complication, and a control group including 80 healthy age and sex-matched subjects. Results of our study showed that neutrophil-lymphocyte ratio (NLR) values were significantly higher in diabetic patients with retinopathy $(\mathrm{p}<0.001)$, neuropathy $(\mathrm{p}=0.025)$ and nephropathy $(\mathrm{p}<0.001)$ than those of diabetic patients without any microvascular complications and healthy control subjects. NLR levels correlated positively with body mass index (BMI) $(r=0.436, p<0.001)$, glycosylated hemoglobin $(\mathrm{HbA1c})(\mathrm{r}=0.526, \mathrm{p}=0.001)$ and erythrocyte sedimentation rate $(\mathrm{ESR})(\mathrm{r}=0.396, \mathrm{p}=0.017)$. Based on the results of this study, we can conclude that neutrophil-lymphocyte ratio (NLR), which is an efficient, simple and stable marker of inflammation, can serve as an important predictor for the presence of microvascular complications in Egyptian patients with type 2 diabetes.
\end{abstract}

Keywords: Neutrophil-Lymphocyte Ratio (NLR), Type 2 Diabetes, Microvascular Complications, Diabetic Retinopathy, Diabetic Nephropathy, Diabetic Neuropathy, Egypt

\section{Introduction}

Patients with diabetes mellitus commonly develop various chronic vascular complications, including macrovascular diseases (heart disease, stroke and peripheral vascular disease) and microvascular diseases (retinopathy, neuropathy and nephropathy) [1]. The inflammatory process plays a crucial role in the pathogenesis of type 2 diabetes and precedes the onset of the disease. Subclinical inflammation contributes to further deepening of metabolic disturbances and finally development of vascular diabetic late complications [2, 3], which are the major cause of morbidity and mortality in diabetic patients [4]. Moreover, there is evidence that chronic inflammation may contribute to both development and acceleration of microangiopathy and macroangiopathy in diabetic patients [5]. Inflammatory cytokines such as TNF- $\alpha$, IL- $1 \beta$, IL- 6 were found to play a central role in the vicious circle of inflammation, endothelial dysfunction and atherosclerosis in patients with diabetic micro- and macrovascular complications [6,7]. Furthermore, previous studies have suggested that chronic low grade inflammation may play a role in the development of insulin resistance, thus might further proceed to development of overt type 2 diabetes [8].

Neutrophil-lymphocyte ratio (NLR) may be considered a novel marker of chronic inflammation. It represents a combination of two markers; neutrophils, which represent the active nonspecific mediator initiating the first line of defense and lymphocytes, representing the regulatory or protective component of inflammation [9]. What might make NLR superior to other leukocyte parameters (e.g. neutrophil, 
lymphocyte and total leucocyte count) is its stability with less influence by physiological, pathological and physical factors $[10,11]$. Therefore, NLR has recently been defined as an essential and potential inflammatory marker in cardiac and non-cardiac disorders [12, 13]. NLR, that can be easily calculated from a simple peripheral blood count, is simpler and cheaper than measuring other inflammatory cytokines, such as IL-6, IL-1 $\beta$ and TNF- $\alpha$ [14]. Few studies have shown that neutrophilia and lymphocytopenia are independent predictors of many morbidities, including diabetic complications [15].

\section{Patients and Methods}

This study was conducted in the Outpatient Clinic of the Diabetes and Metabolism Unit at Alexandria University Hospital between September 2014 and July 2015. Local Ethical Board approval and informed consents from all study subjects were obtained before enrollment. A case control study was carried out on 200 male type 2 diabetic patients, 108 of them were having one or more microvascular complication and 80 healthy subjects, with matched age and sex, as a control group. Data were collected through a predesigned structured questionnaire to collect information about age, smoking habits, type of diabetes, duration of the disease, previous screening for diabetic complications, history of renal disease (dialysis or transplantation), history of retinal laser photocoagulation as well as symptoms of diabetic neuropathy.

For all study subjects, anthropometric measures were assessed with calculation of body mass index (BMI) and measurement of waist circumference (WC) in centimeters. Neurological examination was performed using the 10-grams Semmes-Weinstein monofilament, applying the test on 9 different sites on the plantar surface of the foot and diagnosing sensory neuropathy when less than seven sites were felt by the patient. Vibration Perception Threshold (VPT) was also measured, using a biothesiometer, to define the presence of diabetic neuropathy with a cutoff VPT of more than 25 volts for the diagnosis of loss of protective sensation.

Retinopathy examination was done through fundus examination, performed by an Ophthalmologist, with fully dilated pupils and severity of retinopathy, if any, was assessed. Diabetic retinopathy was graded as no signs of retinopathy, non-proliferative retinopathy or proliferative retinopathy. Urinary albumin-to-creatinine ratio (UACR) was done for all study patients, and repeated whenever positive for confirmation. Patients were classified as having 'no albuminuria' when the UACR is less than $30 \mathrm{mg} / \mathrm{g}$, incipient nephropathy with UACR $30-300 \mathrm{mg} / \mathrm{g}$ or overt nephropathy with values $\geq 300 \mathrm{mg} / \mathrm{g}$. For all study subjects, fasting plasma glucose, glycosylated hemoglobin (HbA1c), erythrocyte sedimentation rate (ESR) as well as estimation of neutrophil-lymphocyte ratio (NLR), by dividing the absolute neutrophil count by the absolute lymphocyte count on a peripheral blood film, were performed.

Statistical analysis of the data: Data were analyzed using IBM SPSS software package version 20.0. Qualitative data were described using number and percent. Quantitative data were described using range (minimum and maximum), mean, standard deviation and median. The distributions of quantitative variables were tested for normality using Kolmogorov-Smirnov test, Shapiro-Wilk test and D'Agstino test. If it reveals normal data distribution, parametric tests were applied. If the data were abnormally distributed, nonparametric tests were used. For normally distributed data, comparison between the two studied groups were done using independent t-test while for more than two groups F-test (ANOVA) was used. Correlations between two quantitative variables were assessed using pearson coefficient. Significance of the obtained results was judged at the $5 \%$ level.

\section{Results}

A total of 280 subjects have been enrolled in this study; 200 type 2 diabetic patients and 80 age- and gender-matched control subjects. Each subject was allocated to one of 3 groups; group I included 108 type 2 diabetic patients with at least one microvascular complication of diabetes (retinopathy, nephropathy and/or neuropathy), group II included 92 type 2 diabetic patients without any microvascular diabetic complication and group III including 80 healthy control subjects. Table 1 shows the baseline characteristics and laboratory data of all studied subjects.

Table 1. Baseline Characteristics and Laboratory Data of the Three Studied Groups.

\begin{tabular}{lllll}
\hline Variable & $\begin{array}{l}\text { Diabetic patients with } \\
\text { complications (group I) } \\
(\mathbf{n = 1 0 8})\end{array}$ & $\begin{array}{l}\text { Diabetic patients without } \\
\text { complications (group II) } \\
(\mathbf{n = 9 2 )}\end{array}$ & $\begin{array}{l}\text { Control subjects (group III) } \\
(\mathbf{n}=\mathbf{8 0})\end{array}$ & P- value \\
\hline Age (years) & $56.19 \pm 7.27$ & $53.60 \pm 6.15$ & $53.50 \pm 6.66$ & $\mathrm{NS}$ \\
Duration of diabetes (years) & $9.78 \pm 7.40$ & $10.21 \pm 5.74$ & - & $\mathrm{NS}$ \\
BMI $\left(\mathrm{kg} / \mathrm{m}^{2}\right)$ & $29.86 \pm 5.25$ & $29.15 \pm 4.03$ & $26.99 \pm 1.69$ & $0.016^{*}$ \\
Waist circumference (cm) & $90.97 \pm 15.75$ & $87.67 \pm 9.83$ & $79.37 \pm 2.76$ & $<0.001^{*}$ \\
FPG (mg/dl) & $181.89 \pm 72.86$ & $198.17 \pm 70.04$ & $82.3 \pm 10.23$ & $<0.001^{*}$ \\
HbA1c (\%) & $10.28 \pm 2.50$ & $8.62 \pm 2.63$ & $5.21 \pm 0.45$ & $<0.001^{*}$ \\
ESR (mm) & & & $10.93 \pm 4.86$ & $<0.001^{*}$ \\
$1^{\text {st }}$ hour & $26.86 \pm 9.89$ & $15.37 \pm 7.19$ & $25.13 \pm 10.86$ & $<0.001^{*}$ \\
$2^{\text {nd }}$ hour & $53.92 \pm 17.79$ & $35.67 \pm 13.43$ & & \\
\hline
\end{tabular}

All parameters were expressed as mean \pm standard deviation.

*: Statistically significant at $\mathrm{p} \leq 0.05$

BMI: body mass index, FPG: fasting plasma glucose, HbA1c: glycosylated hemoglobin, ESR: erythrocyte sedimentation rate, NS: not significant. 
Diabetic patients with microvascular complications (group I) were having higher neutrophil-lymphocyte ratio (NLR), compared with diabetic patients without complications (group II) $(\mathrm{p}<0.001)$ and the control group (group III) $(\mathrm{p}<0.001)$ whereas there was no statistically significant difference between group II and group III as regard the levels of NLR ( $\mathrm{p}=0.65)$ (table 2).
When we classified the severity of diabetic retinopathy, both patients with non-proliferative and those with proliferative retinopathy were having higher NLR compared with diabetic patients without any microvascular complication ( $\mathrm{p}=0.003$ and $\mathrm{p}<0.001$ respectively). However, no significant difference was recorded between patients with both grades of diabetic retinopathy $(\mathrm{p}=0.131)$ (table 3$)$.

Table 2. Differences in White Blood Cell (WBC) Count \& Neutrophil-lymphocyte Ratio (NLR) in the 3 Studied Groups.

\begin{tabular}{|c|c|c|c|c|}
\hline & $\begin{array}{l}\text { Diabetic Patients with } \\
\text { Complications (Group I) } \\
(\mathrm{n}=\mathbf{1 0 8})\end{array}$ & $\begin{array}{l}\text { Diabetic Patients without } \\
\text { Complications (Group II) } \\
(\mathrm{n}=92)\end{array}$ & $\begin{array}{l}\text { Control Subjects (Group III) } \\
(\mathrm{n}=\mathbf{8 0})\end{array}$ & P value \\
\hline \multicolumn{5}{|l|}{ WBCs $\left(\times 10^{3} / \mu \mathrm{L}\right)$} \\
\hline Min. - Max. & $4.31-11.0$ & $4.59-11.0$ & $4.40-7.20$ & \\
\hline Mean $\pm \mathrm{SD}$ & $8.08 \pm 1.89$ & $6.06 \pm 1.50$ & $5.20 \pm 0.80$ & $<0.001^{*}$ \\
\hline Median & 8.16 & 5.69 & 5.0 & \\
\hline Significance between groups & \multicolumn{4}{|l|}{$\mathrm{p}_{1}<0.001^{*}, \mathrm{p}_{2}<0.001^{*}, \mathrm{p}_{3}=0.028^{*}$} \\
\hline \multicolumn{5}{|c|}{ Absolute Neutrophil count $\left(\times 10^{3} / \mu \mathrm{L}\right)$} \\
\hline Min. - Max. & $1.84-8.15$ & $2.12-5.83$ & $1.90-4.40$ & \\
\hline Mean \pm SD & $4.86 \pm 1.49$ & $3.28 \pm 0.93$ & $2.64 \pm 0.62$ & $<0.001^{*}$ \\
\hline Median & 4.70 & 2.93 & 2.56 & \\
\hline Significance between groups & \multicolumn{4}{|l|}{$\mathrm{p}_{1}<0.001^{*}, \mathrm{p}_{2}<0.001^{*}, \mathrm{p}_{3}=0.028^{*}$} \\
\hline \multicolumn{5}{|c|}{ Absolute lymphocyte count $\left(\times 10^{3} / \mu \mathrm{L}\right)$} \\
\hline Min. - Max. & $0.91-3.41$ & $1.49-4.90$ & $1.40-2.90$ & \multirow{3}{*}{0.101} \\
\hline Mean \pm SD & $2.18 \pm 0.64$ & $2.43 \pm 0.91$ & $2.05 \pm 0.42$ & \\
\hline Median & 2.11 & 2.09 & 1.91 & \\
\hline \multicolumn{5}{|l|}{ Neutrophil Lymphocyte ratio } \\
\hline Min. - Max. & $1.07-5.30$ & $0.91-1.96$ & $0.86-2.50$ & \\
\hline Mean $\pm \mathrm{SD}$ & $2.39 \pm 1.01$ & $1.41 \pm 0.30$ & $1.33 \pm 0.38$ & $<0.001^{*}$ \\
\hline Median & 2.11 & 1.41 & 1.40 & \\
\hline Significance between groups & \multicolumn{4}{|l|}{$\mathrm{p}_{1}<0.001^{*}, \mathrm{p}_{2}<0.001^{*}, \mathrm{p}_{3}=0.650$} \\
\hline
\end{tabular}

$\mathrm{p}_{1}$ : $\mathrm{p}$ value for comparing between group I \& group II.

$\mathrm{p}_{2}: \mathrm{p}$ value for comparing between group I \& group III.

$\mathrm{p}_{3}: \mathrm{p}$ value for comparing between group II \& group III.

*: Statistically significant at $\mathrm{p} \leq 0.05$

Table 3. Relationship between Neutrophil-lymphocyte ratio (NLR) and Diabetic Retinopathy.

\begin{tabular}{lllc}
\hline & $\begin{array}{l}\text { Diabetic patients without } \\
\text { complications (n=92) }\end{array}$ & \multicolumn{2}{c}{ Diabetic Retinopathy } \\
& & Non-proliferative (n= 21) & Proliferative (n= 18) \\
\hline Neutrophil Lymphocyte ratio & & $1.11-3.52$ & $1.43-5.30$ \\
Min. - Max. & $0.91-1.96$ & $2.25 \pm 0.72$ & $2.79 \pm 1.45$ \\
Mean \pm SD & $1.41 \pm 0.30$ & 2.27 & 2.20 \\
Median & 1.41 & & $14.483^{*}$ \\
Significance between groups & $\mathrm{p}_{1}=0.003^{*}, \mathrm{p}_{2}<0.001^{*}, \mathrm{p}_{3}=0.131$ & & \\
\hline
\end{tabular}

F: F test (ANOVA), Significance between groups was done using Post Hoc test (LSD)

$\mathrm{p}_{1}$ : between diabetic patients without complications and those with non-proliferative retinopathy

$\mathrm{p}_{2}$ : between diabetic patients without complications and those with proliferative retinopathy

$\mathrm{p}_{3}$ : between patients with proliferative retinopathy and those with non-proliferative retinopathy

*: Statistically significant at $\mathrm{p} \leq 0.05$

Table 4. Relationship between Neutrophil Lymphocyte ratio and Parameters of Peripheral Diabetic Neuropathy.

\begin{tabular}{|c|c|c|c|c|c|c|}
\hline & \multirow{2}{*}{ No. } & \multicolumn{3}{|c|}{ Neutrophil-lymphocyte Ratio (NLR) } & \multirow{2}{*}{$\begin{array}{l}\text { Test of } \\
\text { significance }\end{array}$} & \multirow{2}{*}{ P value } \\
\hline & & Min. - Max. & Mean \pm SD & Median & & \\
\hline \multicolumn{7}{|l|}{ Monofilament: } \\
\hline Normal & 27 & $1.07-2.27$ & $1.74 \pm 0.46$ & 1.86 & \multirow[t]{2}{*}{$5.636^{*}$} & \multirow[t]{2}{*}{$0.023^{*}$} \\
\hline Abnormal & 81 & $1.11-5.30$ & $2.61 \pm 1.06$ & 2.33 & & \\
\hline \multicolumn{5}{|c|}{ Vibration Perception Threshold (VPT): } & \multirow{3}{*}{$9.196^{*}$} & \multirow{3}{*}{$0.005^{*}$} \\
\hline Normal $(<25)$ & 54 & $1.07-3.52$ & $1.93 \pm 0.60$ & 1.93 & & \\
\hline Abnormal $(>25)$ & 54 & $1.43-5.30$ & $2.86 \pm 1.14$ & 2.57 & & \\
\hline Normal & 24 & $1.07-2.27$ & $1.61 \pm 0.51$ & 1.50 & \multirow{2}{*}{$2.706^{*}$} & \multirow{2}{*}{$0.011 *$} \\
\hline Absent & 84 & $1.43-5.30$ & $2.62 \pm 1.01$ & 2.31 & & \\
\hline
\end{tabular}

*: Statistically significant at $\mathrm{p} \leq 0.05$ 
Table 5. Relationship between Neutrophil-lymphocyte ratio (NLR) and Urinary Albumin Creatinine Ratio (UACR).

\begin{tabular}{|c|c|c|c|c|c|}
\hline & \multirow{2}{*}{$\begin{array}{l}\text { Diabetic Patients without } \\
\text { Complications }(\mathrm{n}=92) \\
\text { (Group II) }\end{array}$} & \multicolumn{2}{|c|}{ Urinary Albumin Creatinine Ratio (UACR) } & \multirow[b]{2}{*}{$\mathbf{F}$} & \multirow[b]{2}{*}{ P value } \\
\hline & & $\begin{array}{l}\text { UACR }=30-300 \mathrm{mg} / \mathrm{g} \\
(\mathrm{n}=51)\end{array}$ & $\begin{array}{l}\text { UACR } \geq 300 \mathrm{mg} / \mathrm{g} \\
(\mathrm{n}=24)\end{array}$ & & \\
\hline \multicolumn{6}{|c|}{ Neutrophil-lymphocyte Ratio (NLR) } \\
\hline Min. - Max. & $0.91-1.96$ & $1.07-5.30$ & $1.40-4.99$ & & \\
\hline Mean \pm SD & $1.41 \pm 0.30$ & $2.29 \pm 1.07$ & $2.52 \pm 1.21$ & $10.638^{*}$ & $<0.001^{*}$ \\
\hline Median & 1.41 & 1.99 & 2.22 & & \\
\hline Significance between groups & $\mathrm{p}_{1}<0.001^{*}, \mathrm{p}_{2}=0.001^{*}, \mathrm{p}_{3}=0.484$ & & & & \\
\hline
\end{tabular}

F: F test (ANOVA), Significance between groups was done using Post Hoc test (LSD)

$\mathrm{p}_{1}$ : between diabetic patients with no complications and those with UACR in the range of $30-300 \mathrm{mg} / \mathrm{g}$.

$\mathrm{p}_{2}$ : between diabetic patients with no complications and those withUACR $\geq 300 \mathrm{mg} / \mathrm{g}$.

$\mathrm{p}_{3}$ : between patients with Albumin UACR in the range of $30-300 \mathrm{mg} / \mathrm{g}$ and those with UACR $\geq 300 \mathrm{mg} / \mathrm{g}$.

*: Statistically significant at $\mathrm{p} \leq 0.05$

As regards peripheral diabetic neuropathy, all measured parameters of the disease were significantly associated with higher neutrophil-lymphocyte ratio. Compared with diabetic patients with normal test findings, the mean NLR values were higher in patients who had abnormal monofilament test $(\mathrm{p}=0.023)$, those who were having vibration perception threshold (VPT) more than 25 volts $(\mathrm{p}=0.005)$ and patients with absent ankle reflex $(\mathrm{p}=0.011)$ (table 4$)$.

Based on the urinary albumin to creatinine ratio (UACR), patients with diabetic nephropathy were classified into incipient nephropathy (UACR in the range of $30-300 \mathrm{mg} / \mathrm{g}$ ) and overt nephropathy (UACR $\geq 300 \mathrm{mg} / \mathrm{g}$ ). Both patients with incipient and those with overt nephropathy were having significantly higher NLR values, compared with diabetic patients without any microvascular complication $(p<0.001$ and $\mathrm{p}=0.001$ respectively). However, no significant difference was recorded between patients with both grades of diabetic nephropathy $(\mathrm{p}=0.484)$ (table 5).

Table 6. Relationship between Neutrophil-lymphocyte Ratio and Number of Microvascular Complications.

\begin{tabular}{|c|c|c|c|c|c|c|}
\hline & \multicolumn{3}{|l|}{ Diabetic Patients } & \multirow[b]{2}{*}{$\begin{array}{l}\text { Control } \\
(\mathbf{n}=\mathbf{8 0}) \\
\text { (Group III) }\end{array}$} & \multirow[b]{2}{*}{$\mathbf{F}$} & \multirow[b]{2}{*}{$\mathbf{p}$} \\
\hline & $\begin{array}{l}\text { With No Microvascular } \\
\text { Complications }(\mathrm{n}=92) \\
\text { (Group II) }\end{array}$ & $\begin{array}{l}\text { With Only One } \\
\text { Microvascular } \\
\text { Complication }(n=35)\end{array}$ & $\begin{array}{l}\text { With More than One } \\
\text { Microvascular } \\
\text { Complication }(n=73)\end{array}$ & & & \\
\hline \multicolumn{7}{|l|}{$\begin{array}{l}\text { Neutrophil-lymphocyte ratio } \\
\text { (NLR) }\end{array}$} \\
\hline Min. - Max. & $0.91-1.96$ & $1.07-3.52$ & $1.43-5.30$ & $0.86-2.50$ & & \\
\hline Mean \pm SD & $1.41 \pm 0.30$ & $2.08 \pm 0.78$ & $2.77 \pm 1.11$ & $1.33 \pm 0.38$ & $26.568^{*}$ & $<0.001^{*}$ \\
\hline Median & 1.41 & 2.06 & 2.36 & 1.40 & & \\
\hline Significance between groups & \multicolumn{6}{|c|}{$\mathrm{p}_{1}=0.621, \mathrm{p}_{2}=0.007^{*}, \mathrm{p}_{3}<0.001^{*}$} \\
\hline Significance between groups & \multicolumn{6}{|c|}{$\mathrm{p}_{4}=0.021^{*} \mathrm{p}_{5}<0.001^{*} \mathrm{p}_{6}<0.001^{*}$} \\
\hline
\end{tabular}

F: F test (ANOVA), Significance between groups was done using Post Hoc test (LSD)

$\mathrm{p}_{1}$ : between control subjects (group III) and diabetic patients with no microvascular complications (group II).

$\mathrm{p}_{2}$ : between control subjects (group III) and diabetic patients with one microvascular complication.

$\mathrm{p}_{3}$ : between control subjects (group III) and diabetic patients with more than one microvascular complication.

$\mathrm{p}_{4}$ : between diabetic patients with no complication (group II) and diabetic patients with one complication.

$\mathrm{p}_{5}$ : between diabetic patients with no complication (group II) and diabetic patients with more than one complication

$\mathrm{p}_{6}$ : between diabetic patients with one complication and diabetic patients with more than one complication.

*: Statistically significant at $\mathrm{p} \leq 0.05$

Table 7. Correlation Study between Neutrophil-lymphocyte Ratio (NLR) and other Studied Variables.

\begin{tabular}{lll}
\hline Study Parameter & r & P value \\
\hline Patients Age (years) & 0.123 & 0.475 \\
Duration of Diabetes (years) & -0.063 & 0.716 \\
Body mass Index (BMI) & $0.736^{*}$ & $<0.001^{*}$ \\
Systolic Blood Pressure (SBP) & 0.253 & 0.136 \\
Diastolic Blood Pressure (DBP) & 0.253 & 0.137 \\
Waist Circumference (WC) & 0.051 & 0.766 \\
White Blood Cell (WBC) Count & 0.208 & 0.224 \\
Fasting Plasma Glucose (FPG) & 0.026 & 0.881 \\
Glycosylated Hemoglobin (HbA1c) & $0.526^{*}$ & $0.001^{*}$ \\
Erythrocyte Sedimentation Rate (ESR) 1 ${ }^{\text {st hour }}$ & $0.441^{*}$ & $0.007^{*}$ \\
Erythrocyte Sedimentation Rate (ESR) 2 ${ }^{\text {nd }}$ hour & $0.396^{*}$ & $0.017^{*}$ \\
\hline
\end{tabular}

r: Pearson coefficient

*: Statistically significant at $\mathrm{p} \leq 0.05$ 
Interestingly, diabetic patients with more than one microvascular complications showed significantly higher NLR levels compared with those who were having only one microvascular complication (retinopathy, neuropathy or nephropathy) $(\mathrm{p}<0.001)$ (table 6).

Significant positive correlation was found between NLR and each of the following studied parameters: BMI $(\mathrm{r}=0.736$, $\mathrm{p}<0.001), \mathrm{HbA1c}(\mathrm{r}=0.526, \mathrm{p}=0.001)$ and $\mathrm{ESR}(\mathrm{r}=0.441$, $\mathrm{p}=0.007)($ table 7$)$

\section{Discussion}

The most important finding of our study was that neutrophil-lymphocyte ratio (NLR) levels were significantly higher in diabetic patients with microvascular complications (retinopathy, nephropathy and peripheral neuropathy) than among diabetic patients with no complications and the control group $(p<0.001)$. Several epidemiological studies have previously highlighted that chronic low grade inflammation is associated with diabetes mellitus [8].

Currently, there is evidence that diabetic retinopathy and other complications of diabetes may be considered to be a state of generalized inflammation [5, 16, 17]. Clinical studies have shown elevated levels of pro-inflammatory cytokines in the vitreous fluid of patients with proliferative diabetic retinopathy, which are related to the activity and progression of retinal injury. These data highlighted the central and causal role of chronic low-grade subclinical inflammation in the pathogenesis of diabetic retinopathy [18]. In our study, the mean NLR among patients with retinopathy was significantly higher than among diabetic patients without retinopathy or any other microvascular diabetic complication $(p<0.001)$. The mean NLR was higher in patients with proliferative diabetic retinopathy than in patients with non-proliferative diabetic retinopathy, but there was no statistical significance between the 2 groups. Ulu $\mathrm{S}$ et al from the Faculty of Medicine, Afyon Kocatepe University, Turkey, found that NLR values of the diabetic patients with diabetic retinopathy were higher than those of patients without retinopathy [15]. Another study, carried out by Yue $\mathrm{S}$ et al in the Fengyutan Health Care Center, Shenhe District, Shenyang City, China, has similarly showed that patients with diabetic retinopathy had higher NLR values than diabetic patients without evidence of the disease [19]. In contrast to our results, Ciray $\mathrm{H}$ et al, from the Department of Internal Medicine, Karaman State Hospital, Karaman, Turkey, found that NLR was not significantly different between patients with and without diabetic retinopathy, arguing that there is no independent association between NLR and the presence of retinopathy in patients with type 2 diabetes [20].

Diabetic neuropathy develops as a result of hyperglycemia-induced local metabolic, enzymatic and microvascular changes. It has been demonstrated that endogenous TNF- $\alpha$ production is accelerated with microvascular permeability, hypercoagulability and nerve damage, thus initiating and promoting the development of characteristic lesions of diabetic polyneuropathy [21]. In our study, we found that NLR was significantly higher among patients with diabetic neuropathy, compared with patients without evidence of peripheral neuropathy. Neutrophillymphocyte ratio was consistently higher among diabetic patients with loss of protective lower extremity sensation, detected by abnormal monofilament test $(\mathrm{p}=0.023)$, abnormal vibration perception threshold (VPT) $(p=0.005)$ and absent ankle reflex $(\mathrm{p}=0.004)$. To the best of our knowledge, there is no other clinical studies investigating the relationship between NLR and diabetic peripheral neuropathy. However, there are a few studies that have tested the association of chronic subclinical inflammation and diabetic peripheral neuropathy. Herder $\mathrm{C}$ et al, from the Institute for Clinical Diabetology, German Diabetes Center, Heinrich Heine University, Düsseldorf, Germany, found that several immune mediators might be associated with the development of diabetic polyneuropathy [22].

Diabetic nephropathy is a common diabetic complication, but its pathogenesis remains unclear. Several studies have reported an association between the presence of diabetic nephropathy and states of chronic inflammation. Few studies examined the relationship between white blood cells (WBC) count and urinary albumin excretion in diabetic patients and demonstrated that higher WBC counts were related to increased urinary albumin excretion rates [23,24]. Asfar B et al, in the Division of Nephrology, Konya Numune State Hospital, Konya, Turkey, have shown that neutrophillymphocyte ratio (NLR) could be related to the presence of diabetic nephropathy and it has been correlated as an indicator of end stage renal disease [25]. In our study, the mean NLR among patients with diabetic nephropathy was significantly higher than among diabetic patients without nephropathy or any other microvascular diabetic complication $(\mathrm{p}<0.001)$. NLR was higher among patients with overt nephropathy, compared with that in incipient nephropathy, but this did not reach a statistical significance. In agreement with our results, Huang $\mathrm{W}$ et al, from the Department of Endocrinology, Zhujiang Hospital, Southern Medical University, Guangzhou, China, have found that neutrophil-lymphocyte ratio values were significantly higher in diabetic patients with evidence of nephropathy $(2.48 \pm 0.59)$ than in diabetic patients without nephropathy $(2.20 \pm 0.62)$ and healthy control subjects (1.80 \pm 0.64$)$ [26]. Similarly, Asfar B at al studied the relationship between neutrophil lymphocyte ratio and urinary protein and albumin excretion in type 2 diabetic patients who are recently diagnosed, and reported that increased NLR was independently associated with both 24 -hour urinary protein $(\mathrm{p}<0.001)$ and urinary albumin excretion $(\mathrm{p}<0.001)$ in newly diagnosed Turkish patients with type 2 diabetes [25].

\section{Conclusions}

We could highlight here the importance of a routine assessment the neutrophil-lymphocyte ratio (NLR), which can be easily calculated from a simple peripheral blood count and, therefore, is much simpler and cheaper than measuring more sophisticated inflammatory cytokines in patients with diabetes. Based on the results of our study, neutrophillymphocyte ratio (NLR), which is an efficient and stable marker of inflammation, can serve as an important predictor 
for the presence of microvascular diabetic complications, namely retinopathy, neuropathy and/or nephropathy, in Egyptian patients with type 2 diabetes.

\section{References}

[1] Reyden L, Standhl E, Bartnik M, BergheGVd, Betteridge J. Guidelines on diabetes, pre-diabetes, and cardiovascular disease. Eur Heart J. 2007: 1-72.

[2] Pisarczyk-Wiza D, Zozulinska-Ziolkiewicz D, Wysocki H, Wierusz-Wysocka B. Increase in glycemia stimulates reactive oxygen species (ROS) production by polymorphonuclear neutrophils in type 2 diabetic patients. J Pre-clin Clin Res 2011; 5: 22-7.

[3] Tian JY, Yang Y, Cheng Q, Huang HE, Li R, Jiang GX, et al. Association of WBC count and glucose metabolism among Chinese population aged 40 years and over. Diabetes Res Clin Pract 2008; 82: 132-8.

[4] Narayan KM, Gregg EW, Fagot-Campagna A, Engelau MM, Vinicor F. Diabetes: a common, growing, serious, costly and potentially preventable public health problem. Diabetes Res Clin Pract 2000; 50: S77-84.

[5] Fujita T, Hemmi S, Kajiwara M, Yabuki M, Fuke Y, Satomura $\mathrm{A}$, et al. Complement-mediated chronic inflammation is associated with diabetic microvasvular complication. Diabetes Metab Res Rev 2013; 29: 220-6.

[6] Nguyen D, Shaw L, Grant M. Inflammation in the pathogenesis of microvascular complications in diabetes. Front Endocrinol 2012; 3: 170.

[7] Rajala MW, Scherer PE. Mini review: the adipocyte-at the crossroads of energy homeostasis, inflammation, and atherosclerosis. Endocrinology 2003, 144(9): 3765-73.

[8] Pitsavos C, Tampourlou M, Panagiotakos DB, Skoumas Y, Chrysohoou C, Nomikos T, et al. Association Between LowGrade Systemic Inflammation and Type 2 Diabetes Mellitus Among Men and Women from the ATTICA Study. Rev Diabet Stud 2007; 4(2): 98-104.

[9] Bhutta H, Agha R, Wong J, Tang TY, Wilson YG, Walsh SR. Neutrophil lymphocyte ratio predicts medium-term survival following elective major vascular surgery: a cross sectional study. Vasc Endovascular Surg 2011; 45: 227-31.

[10] Matthews DR, Hosker JP, Rudenski AS, Naylor BA, Treacher DF, Turner RC. Homeostasis model assessment: Insulin resistance and beta cell function from fasting plasma glucose and insulin concentrations in man. Diabetologia 1985; 28: 412-19.

[11] Gibson PH, Croal BL, Cuthbertson BH, Small GR, Ifezulike AI, Gibson G, et al. Preoperative neutrophil-lymphocyte ratio and outcome from coronary artery bypass grafting. Am Heart J 2007; 154: 995-1002.

[12] Tamhane UU, Aneja S, Montgomery D, Rogers EK, Eagle KA, Gurm HS. Association between admission neutrophil to lymphocyte ratio and outcomes in patients with acute coronary syndrome. Am J Cardiol 2008; 102: 653-7.

[13] Núñez J, Núñez E, Bodí V, Sanchis J, Miñana G, Mainar L, et al. Usefulness of the neutrophil to lymphocyte ratio in predicting long-term mortality in ST segment elevation myocardial infarction. Am J Cardiol 2008; 101: 747-52.

[14] Turkmen K, Guney I, Yerlikaya FH, Tonbul HZ. The relationship between neutrophil-to-lymphocyte ratio and inflammation in end-stage renal disease patients. Renal Failure 2012; 34: 155-9.

[15] Ulu S, Bucak A, Ulu MS, Ahsen A, Duran A, Yucedag F, et al. Neutrophil-lymphocyte ratio as a new predictive and prognostic factor at the hearing loss of diabetic patients. Eur Arch Otorhinolaryngol 2013; 13: 2734-43.

[16] Ross R. Atherosclerosis an inflammatory disease. N Engl J Med 1999; 340: 115-26.

[17] Lim LS, Tai ES, Mitchell P, Wang JJ, Tay WT, Lamoureux E, et al. C-reactive protein, body mass index, and diabetic retinopathy. Invest Ophthalmol Vis Sci 2010; 51: 4458-63.

[18] Joussen AM, Poulaki V, Le ML, Koizumi K, Esser C, Janicki $\mathrm{H}$, et al. A central role for inflammation in the pathogenesis of diabetic retinopathy. Faseb J 2004; 18(12): 1450-2.

[19] Yue S, Zhang J, Wu J, Teng W, Liu L, Chen L. Use of the monocyte-to-lymphocyte ratio to predict diabetic retinopathy. Int J Environ Res Public Health 2015; 12: 10009-19.

[20] Ciray H, Aksoy A H, Ulu N, Cizmecioglu, Gaibov A, Solak Y. Nephropathy, but not angiographically proven retinopathy is associated with neutrophil to lymphocyte ratio in patients with type 2 diabetes. Exp Clin Endocrinol Diabetes 2015; 123(5): 267-71.

[21] Satoh J, Yagihashi S, Toyota T. The possible role of tumor necrosis factor-alpha in diabetic polyneuropathy. Exp Diabesity Res 2003; 4: 65-71.

[22] Herder C, Lankisch M, Ziegler D, Rathmann W, Koenig W, Illig $\mathrm{T}$, et al. Subclinical Inflammation and Diabetic Polyneuropathy. Diabetes Care 2009; 32: 680-2.

[23] Tong PC, Lee KF, So WY, Ng MH, Chan WB, Lo MK, et al. White blood cell count is associated with macro- and microvascular complications in Chinese patients with type 2 diabetes. Diabetes Care 2004; 27: 216-22.

[24] Cavalot F, Massucco P, Perna P, Traversa M, Anfossi G, Trovati M. White blood cell count is positively correlated with albumin excretion rate in subjects with type 2 diabetes. Diabetes Care 2002; 25: 2354-5.

[25] Asfar B. The relationship between neutrophil lymphocyte ratio with urinary protein and albumin excretion in newly diagnosed patients with Type 2 Diabetes. Am J Med Sci 2013; 347(3): $217-20$

[26] Huang W, Huang J, Liu Q, Lin F, He Z, Zeng Z, et al. Neutrophil-lymphocyte ratio is a reliable predictive marker for early-stage diabetic nephropathy. Clin Endocrinol 2015; 82: 229-33. 